\title{
Massive open online courses (MOOCs) for long-distance education in geriatric medicine across Europe
}

\author{
A pilot project launched by the consortium of the project "Screening for Chronic Kidney \\ Disease among Older People": SCOPE project
}

\begin{abstract}
Regina Roller-Wirnsberger ${ }^{1}$ (1) - Sabine Zitta ${ }^{2} \cdot$ Carolin Herzog $^{2} \cdot$ Hannah Dornan $^{1} \cdot$ Sonja Lindner ${ }^{1}$. Herwig Rehatschek ${ }^{3}$. Florian Hye ${ }^{3}$ - Lea Kolosovski ${ }^{1}$. Gerhard Wirnsberger ${ }^{2}$ - Andrea Corsonello ${ }^{4}$. Lisanne Tap ${ }^{5}$. Tomasz Kostka $^{6}$. Agnieszka Guligowska ${ }^{6}$. Francesco Mattace-Raso ${ }^{5}$. Pedro Gil ${ }^{7}$. Lara Guardado Fuentes ${ }^{7}$. Rada Artzi-Medvedik $^{8,9} \cdot$ Ilan Yehoshua ${ }^{9} \cdot$ Francesc Formiga $^{10} \cdot$ Rafael Moreno-Gonzalez $^{10}$. Cornel Sieber ${ }^{11,12}$. Ellen Freiberger ${ }^{11,12}$. Johan Ärnlöv ${ }^{13,14}$. Axel C. Carlsson ${ }^{14}$. Fabrizia Lattanzio ${ }^{4}$ on behalf of SCOPE investigators
\end{abstract}

Received: 11 September 2019 / Accepted: 9 October 2019 / Published online: 16 October 2019

(c) The Author(s) 2019

\section{Key summary points}

Aim The aim of the paper is to give insight into MOOCs in general and to specifically describe a MOOC developed in the course of the SCOPE project "Screening for Chronic Kidney Disease (CKD) among older People across Europe".

Findings The major target of the MOOC was the improvement of knowledge for a broad audience. The SCOPE MOOCs are freely accessible, structured in three modules, offer additional learning material and guarantee knowledge dissemination about aging and chronic kidney diseases.

Message The MOOCs represent a contemporary example of how modern technology is supporting a transition to modern training in geriatrics.

\section{Abstract}

Purpose To cover the increasing need for professional knowledge, skills and competences in the care of older people, new learning techniques have been developed. Using the Internet to provide educational material has come into focus of many

Regina Roller-Wirnsberger

Regina.Roller-Wirnsberger@medunigraz.at

1 Department of Internal Medicine/Geriatrics, Medical University of Graz, Auenbruggerplatz 15, $8036 \mathrm{Graz}$, Austria

2 Division of Nephrology, Department of Internal Medicine, Medical University of Graz, Graz, Austria

3 Executive Department Teaching with Media, Medical University of Graz, Graz, Austria

4 Italian National Research Center on Aging (INRCA), Ancona, Fermo and Cosenza, Italy

5 Section of Geriatric Medicine, Department of Internal Medicine, Erasmus MC University Medical Center, Rotterdam, The Netherlands

6 Department of Geriatrics, Healthy Ageing Research Centre, Medical University of Lodz, Lodz, Poland

7 Department of Geriatric Medicine, Hospital Clinico San Carlos, Madrid, Spain
8 The Recanati School for Community Health Professions at the Faculty of Health Sciences at Ben-Gurion University of the Negev, Beersheba, Israel

9 Maccabi Healthcare Services Southern Region, Tel Aviv, Israel

10 Geriatric Unit, Internal Medicine Department, Bellvitge University Hospital-IDIBELL, L'Hospitalet de Llobregat, Barcelona, Spain

11 Institute for Biomedicine of Aging, Friedrich-Alexander-Uni versität Erlangen-Nürnberg, Erlangen, Germany

12 Department of General Internal Medicine and Geriatrics, Krankenhaus Barmherzige Brüder Regensburg, Regensburg, Germany

13 School of Health and Social Studies, Dalarna University, Falun, Sweden

14 Division of Family Medicine and Primary Care, Department of Neurobiology, Care Sciences and Society, Karolinska Institutet, Huddinge, Sweden 
academic institutions as the learning content can easily be transferred to a larger audience. Since the first launch of a "massive open online course" (MOOC) in 2008, this educational format has raised increasing interest among education experts. The current publication provides insight into the new format of MOOCs in general and specifically describes a MOOC developed by a Pan-European Consortium "Screening for Chronic Kidney Disease (CKD) among Older People across Europe" (SCOPE), a project funded by the European Commission under the umbrella of the Horizon 2020 program.

Methods Technical background, learning theories and content of the MOOC of the SCOPE project are presented in this overview.

Results The MOOC of the SCOPE project is provided on the MOOC ICT platform iMoox. The courses are built up of video clips, textual descriptions, graphics, animations and audio designed with a clear structure and learning goals. The concise video clips with a maximum length of 15-20 min are equipped with additional learning material such as documents, links and asynchronous communication opportunities.

Conclusion MOOCs are recognized as a contemporary approach to transfer required knowledge and skills not only in general but also in geriatric medicine, as the health and social care environment is ever-changing and becoming more complex.

Keywords Chronic kidney disease $\cdot$ Aging $\cdot$ Education $\cdot$ Massive open online course $\cdot$ MOOC $\cdot$ e-Learning

"What we need to know for tomorrow is more important than what we know today [1]".

\section{Background on geriatric training}

Europe is facing a demographic transition: The European population is aging considerably and this trend is likely to continue. To face the ongoing demographic shifts, the World Health Organization (WHO) reinforces the need for radical changes in organization and delivery of health care, including education and training of health and social care professionals [2]. In this context, key stakeholders involved into complex care of older people are medical doctors, alongside nurses, dieticians, physiotherapists, gerontologists and social care workers amongst many others.

To cover the increasing need for professional knowledge, skills and competences in the care of older people, the European Geriatric Medicine Society (EuGMS), in collaboration with the European Medical Specialist Society for Geriatric Medicine (UEMS-GMS), has advocated for core knowledge and skills to be acquired by all undergraduate medical students across European member states [3]. This work builds an important step to assure that future professionals caring for older people across Europe will be able to face the needs of this increasingly larger group of patients.

These examples prove the raising awareness about ongoing, contemporary education and training in the field of geriatric healthcare. In this regard, new pedagogical approaches that meet current requirements and principles are emerging. One option to assure homogenous training standards and delivery of comparable content is the provision and use of online training sources. Those online courses and training materials offer the opportunity of use for blended learning training formats. Blended learning models have already been proven a successful learning experience for medical students also in geriatric medicine [4]. Given these recent developments, the internet has become an important resource for teachers and students on all levels of education and training [5], also helping students from diverse backgrounds to explore and build career portfolios to enter health-related professions [6] and the interest to access platforms which openly and widely share knowledge, information or educational material is increasing.

A recent development in online education is illustrated by massive open online courses (MOOCs). Renowned universities such as Harvard Medical School, the Massachusetts Institute of Technology (MIT) and Berkley University amongst others and profit organizations have started to create platforms for massive open online education, covering a variety of topics. More recently, MOOCs have been developed within international cooperative partnerships [7] and have been used to disseminate knowledge generated throughout international collaborations [8].

The current article provides background information on MOOCs in general, and specifically describes a MOOC recently developed and launched by a Pan-European consortium under the umbrella of the international project "Screening for Chronic Kidney Disease (CKD) among Older People across Europe" (SCOPE), which is funded by the European Commission (EC) under the umbrella of the Horizon 2020 program (grant agreement number 634869) [9].

\section{Background on massive open online courses (MOOCs)}

MOOCs are open online courses in which anyone can participate usually free-of-charge. In addition to traditional course material such as filmed lectures, supplementary resources such as textbooks are recommended to the participants to support their self-directed studies. Some MOOCs also 
provide synchronous and asynchronous interactivities in terms of video conferencing tools and forums among students, professors, experts, as well as to give immediate feedback during quick quizzes and assignments [10]. MOOCs are structured in "modules" or "courses" and are usually spaced over a fixed period of time where learners work through the material at an individual pace.

A MOOC can be characterized by two dimensions: the massiveness and the openness. "Massiveness" characterizes the aim to reach thousands of experts, students and other participants. The "openness" may be defined in terms of open access, open structure, open educational resources, open collaboration, open accreditation, open-source code, open data [11] and open to new ideas and solutions. Seen from the learner's perspective, the openness is characterized by open choice of topic and learning resource, free access, the open and self-directed organization of learning activities and possible collaborations [12]. Seen from a teacher's perspective some MOOCs-such as the iMoox platform (https://imoox.at)—offer open educational resources (OER), meaning that all learning material provided in the MOOC courses may be reused, and sometimes even modified, in own lectures.

Assessment models for MOOCs vary, from simple multiple-choice questions (MCQ), through peer-reviewed feedback and more formal modes of assessment. An interesting recent innovation for assessment is the use of open "badges". The concept is simple: learners can apply for badges demonstrating their completion of a MOOC and can further show their earned badges on the places that matter for them.

It was found that students that were enrolled in MOOCs showed high levels of obligation and were self-motivated to self-learn through a variety of novel educational resources, such as video clips, learning activities and animations. In addition, the MOOC participants wished to continue learning with the MOOC methodology [13].

\section{Educational theories underlying the concept of MOOCs}

Recent progress in neuroscience has improved our understanding of how humans learn. Individual learning is a very complex process including cognitive as well as emotional processes [14]. The most recent ideas on technology-based learning were proposed by Siemens [1], who advocates for the concept of "connectivism" as a learning theory, i.e., that learning takes place in a community of individuals who are interested in the same topic. Siemens suggested that "connectivism" may be a relevant learning theory underlying technology-based learning processes [15]. It is assumed by educational experts that "learning by connecting people" supports the learning progress in technology-based learning; however, learning of single participants may still be explained by traditional learning theories such as "cognitivism", "behaviorism" and "constructivism" as the main underlying theories.

Many of the learning techniques used in daily teaching at universities focus on "cognitivism learning", the simple collection of knowledge. It has also been shown that simple knowledge transfer can nowadays be mostly "off-loaded" to technology-based learning sets [16].

Due to the "behaviorism" learning theory, knowledge gain is largely unpredictable as it is highly influenced by the individual learner's attitude (the "black box theory") and learning success is often related to change in behavior of students and learners [17].

According to the "constructivism" learning theory, knowledge is created through personal experiences of learners in the attempt to understand the mechanisms underlying the experiences made [18]. Constructivist learning theories accept that real-life learning settings are often complex and unstructured. Therefore, it is well established to combine these real-life learning sets with traditional classroom teaching. This can help to emerge unstructured learning content and to prepare learners for integration of this concept into a dynamic life-long learning approach. Therefore, it makes sense-also in geriatric medicine-to combine learning offers for knowledge gain with real-life setting teaching activities.

The most interesting new aspect in technology-based learning is the impact and benefit drawn from the networks and social complexities during the learning process. Connecting people via computer networks and social networks allows students and learners to easily act as an integrated common entity and exchange knowledge. This new approach in learning is built in Siemens theory of "connectivism" as well as in the "constructivism" theory and in combination may aid geriatric training for health care professionals.

\section{Type of MOOCs mostly used for adult learning}

There are a variety of different pedagogical approaches being adopted in different MOOCs, some emphasizing individual learning through interactive materials, others focusing more on social learning and network interaction. In this context, the more traditional MOOCs or xMOOCs help students to acquire knowledge, but do not encourage students to create new knowledge themselves [19]. Depending on the courses, the content is presented in videos, texts or pictures and interaction with teachers or tutors through blogs, forums, chatrooms or Skype sessions may be provided. Hence, this format is chosen if the learning content addresses university or college courses. When completing 
an XMOOC participants will receive a confirmation of participation usually stating the module name, the name of the teacher and the learning time. For a more formal certificate, the providers usually charge a small fee.

In his concept of connectivism, Siemens describes a model where communities of people interested in the same topic create new knowledge during active interaction and communication out of pre-existing knowledge [1]. Those more interactive MOOCs are called cMOOCs. cMOOCs reflect the learning concept, postulated by Siemens as a learning tool to enhance the learning outcome.

From the pedagogical and psychological view, there is not much of a difference between traditional distance courses and MOOCs, as far as the learning content is concerned. The difference lies in the openness and massiveness as well as the connectivism used in MOOCs.

\section{The project "Screening for chronic kidney disease among older people across Europe" (SCOPE)}

The SCOPE project (screening for chronic kidney disease among older people across Europe, grant agreement number 634869) was funded under the umbrella of the Horizon 2020 program of the European Commission (EC) in 2015. The project involves nine partners across Europe and Israel and aims at developing new standards in diagnostics and treatment of older citizens at risk for chronic kidney disease (CKD), as screening programs in Europe are highly heterogeneous, fragmented and in most cases based on opportunistic rather than structured assessments of patients [20, 21]. During the SCOPE project, the impact of an innovative comprehensive screening methodology specifically targeting CKD among older people across Europe is addressed. Data resulting from the 2-year observational cohort study will allow building evidence for an effective and person-centered complex care management for older patients suffering from CKD. Translation of this new complex care pathway into daily clinical practice will be achieved by creating knowledge and skills in as many as possible health care professionals involved in the care of older patients globally.

As the consortium identified a large community possibly interested in the new findings of the SCOPE project, the partners chose an online educational tool with utmost openness and massiveness to transfer knowledge around CKD to persons interested and concerned not only at the countries involved in the SCOPE study. The major target group identified was younger colleagues (i.e., medical and nursing students) during their first years of education and training as well as general practitioners. All participants should have a basic understanding of aging processes with a special focus on kidney function, also corresponding with the recommendations published by EuGMS and UEMSGMS [3].

\section{MOOC of the SCOPE project}

The primary outcome of the MOOC is "to increase knowledge on chronic kidney disease in old age and its impact on morbidity and cognitive as well as physical functionality". The secondary outcome is "to inform about methods to determine kidney function in older patients and to inform about complex care strategies in daily clinical practice".

As may be seen from these objectives, the major target of the project was improvement of knowledge for a broad audience. This goal may be achieved by xMOOCs as they have been proven to support the adult learning theories of "cognitivism" and knowledge transfer may be off-loaded to technology-based learning sets. Additional outcomes and experiences to be achieved are learning preferences of the participants, the level of satisfaction with the course content or the completion and drop-out rates of the course. It was assumed by the consortium that most of the target audience of younger colleagues would be familiar with technologybased learning sets and that it may be easy to encourage students to attend the MOOC.

\section{Structure and content of the SCOPE MOOC}

The MOOC designed by the SCOPE project is provided on the MOOC ICT platform iMOOX (http://imoox.at). The platform is based on the open-source software Moodle ${ }^{\mathrm{TM}}$ [22].

In comparison to other MOOC platforms such as edX, Coursera and Udacity, the iMoox platform offers its courses as open educational resources (OER) under CC license [23]. This ensures not only free usage of the content but also re-usage of the content in other teaching scenarios and it guarantees dissemination of knowledge to interested people all over the world.

Technically, the courses are built up of video clips, textual descriptions, graphics, animations and audio. The production of the courses is solely done by the Medical University of Graz, Austria, utilizing high-definition cameras, micros and Adobe Premiere for video editing and rendering. For the production of animations, Cinema 4D [24] is used.

All courses of the SCOPE MOOC are built as XMOOCs, still offering an interactive mode during the first launch of the course. Within the initial-guided course, a teacher is available guiding students through the whole MOOC. This involves regular involvement of the students and some kind of schedule, e.g., every 2 weeks one course has to be finished. Self-directed learning modules lack teacher-based guidance or support; however, they offer the benefit of supporting adult learning theories [25]. 
In general, the three courses provided are designed with a clear structure (chapters) and learning goals, short and concise video clips with a maximum length of 15-20 min, as well as additional learning material such as documents, links and asynchronous communication possibilities. The three courses include following topics: (1) aging and impact on kidney structure and function; (2) methods to determine kidney function in old age; and (3) complex care management of older patients with chronic kidney disease.

Following the attendance in a MOOC, participants are offered an online assessment as foreseen in the concept for online educational events (web-based trainings) [26]. Every participant who has successfully passed the assessment after all modules with a rating of at least $75 \%$ will receive a SCOPE "Certificate" as a confirmation of their participation in the course. There is a maximum of five trials for each assessment.

The iMoox platform currently hosts courses in English and German. As the consortium includes partners from different countries, all courses were produced in English language and will potentially be offered with subtitles and text translations in other languages (German, Italian, Spanish, Dutch, Polish, Hebrew, Swedish and French).

\section{Pros and cons using a MOOC format for long-distance geriatric education}

One of the advantages of the MOOC format is the free access and the possibility to use the MOOC content as required in local settings of universities. As a matter of fact, the content can be added to different blended learning formats, such as flipped classrooms and other techniques [4, 27].

This will give the opportunities to offload learning content to self-directed learning sets, while capturing the opportunity to work with the MOOC students on a case-based scenario, during face-to-face teaching in classroom or seminars. Active learning strategies (such as opportunities for students to participate, self-direct, and engage in their own learning) are not only supported by adult learning theories but have also been shown to be beneficial to long-term learning and the development of self-directed learning skills [28].

Technology nowadays largely influences our communication pathways. In general, learning is built on communication processes that adapt to a learner's need and environment; therefore, it is highly individualized. We aim that the technology-based training offer or "e-learning" developed during the SCOPE project addresses the modern way of communication, and we hope that it will be well accepted in medical faculties across Europe.

The stakeholders around a MOOC are the learners who participate in the MOOCs, the tutors who facilitate participation of learners and encourage them to use the learning material and the teachers who design and assess the learning content of a course. If geriatricians across Europe and abroad find the MOOC presented in this publication feasible for integration in their traditional and local educational geriatric training offers and will use the educational toolkit within their geriatric curricula, then students and learners will be retained within a course. It is assumed in the literature that retention rates of students in MOOCs strongly depend on the way MOOCs are prepared and especially offered to learners [29]. This also strongly affects acceptance and use of the courses by students. Active involvement of many geriatricians teaching students at medical faculties and universities will help to reinforce completion rates of the new MOOC developed by the SCOPE consortium [29].

It is important that the quality assurance agencies for higher education take the rate of course and degree of completion as one of the quality criteria during their audits. This practice is based on the intention to ensure value for the financial investment in technology-based education and to protect students and learners from poorly designed educational offers.

As a paradox, the successful completion of xMOOC courses does not automatically lead to official credits transferable to studies at universities. In most XMOOC-formats, learners are provided only a confirmation of participation, not an official certificate. However, usually for a small fee, official certificates are sometimes provided which are more likely to be accepted by foreign universities. When integrating the MOOC content into the official study plan of a university, e.g., by blended learning, students of this university have the opportunity to accredit the learning effort within the European credits system (ECTS), to overcome this shortcoming.

\section{Conclusion}

The current publication presents the rationale for a massive open online educational course (MOOC) containing three modules on aging and chronic kidney disease, developed by the SCOPE consortium. The MOOC introduced in this publication is pioneer work for different reasons:

In geriatric education, it is important to shift training from knowledge recall to development of skills and translation of knowledge into the work within multi-professional teams. Due to rapidly evolving knowledge in the geriatrics field, it is also important to develop skills to find and use information effectively. In this respect, there is a need to enable learners to develop twenty-first century digital literacy skills [30], and to equip them for an increasingly complex and changing societal context. The MOOC presented in this publication aims at supporting these new dimensions within 
the topic of chronic kidney disease and its management in older patients with complex care needs. The MOOCs represent a contemporary example of how modern technology can disrupt the status quo of education and are supporting a transition to modern training, also in geriatric medicine.

Acknowledgements Open access funding provided by Medical University of Graz.

Funding This article was funded by Horizon 2020 (Grant Agreement 634869).

\section{Compliance with ethical standards}

Conflict of interest This work was supported by the European Commission, Grant Agreement Number 634869. None of the authors has any other potential conflict of interest.

Ethical approval This article does not contain any studies with human participants or animals performed by any of the authors.

Informed consent For this type of article formal consent is not required. All partners involved have signed a disclosure of interest form as well as a commitment to the EU data protection regulation.

Open Access This article is distributed under the terms of the Creative Commons Attribution 4.0 International License (http://creativeco mmons.org/licenses/by/4.0/), which permits unrestricted use, distribution, and reproduction in any medium, provided you give appropriate credit to the original author(s) and the source, provide a link to the Creative Commons license, and indicate if changes were made.

\section{References}

1. Siemens G (2005) Connectivism: a learning theory for the digital age. Int J Instr Technol Distance Learn 2(1):3-10

2. World Health Organization (2015) World report on ageing and health. WHO Library Cataloguing-in-Publication Data, Geneva

3. Masud T, Blundell A, Gordon AL, Mulpeter K, Roller R, Singler $\mathrm{K}$ et al (2014) European undergraduate curriculum in geriatric medicine developed using an international modified Delphi technique. Age Ageing 43(5):695-702

4. Duque G, Demontiero O, Whereat S, Gunawardene P, Leung O, Webster P et al (2013) Evaluation of a blended learning model in geriatric medicine: a successful learning experience for medical students. Australas J Ageing 32(2):103-109

5. Liyanagunawardena T, Adams A, Williams S (2013) MOOCs: a systematic study of the published literature 2008-2012. Int Rev Res Open Distance Learn 14(3):1492-3831

6. Simon MA, Taylor S, Tom LS (2019) Leveraging digital platforms to scale health care workforce development: the career 911 massive open online course. Prog Community Health Partnersh Res Educ Action 13(5):123-130

7. Coursera Inc (2012) Coursera. https://www.coursera.org/. Accessed 9 Sept 2019

8. WARU (2019) WARU. https://waru.org.uk/cms/projects/facet/ facet-mooc/. Accessed 9 Sept 2019

9. IRCCS-INRCA (2016) SCOPE. http://www.scopeproject.eu/. Accessed 9 Sept 2019

10. de Jong PGM, Pickering JD, Hendriks RA, Swinnerton BJ, Goshtasbpour F, Reinders MEJ (2019) Twelve tips for integrating massive open online course content into classroom teaching. Med Teach 1-5

11. Pilli O, Admiraal W (2016) A taxonomy of massive open online courses. Contemp Educ Technol 7(3):223-240

12. El Mawas N, Gilliot JM, Garlatti S, Euler R, Pascual S (2018) Towards personalized content in massive open online courses. In: 10th International conference on computer supported education, Funchal

13. Chan MM, Barchino R, Medina-Merodio JA, de la Roca M, Sagastume F (2019) MOOCs, an innovative alternative to teach first aid and emergency treatment: a practical study. Nurse Educ Today 79:92-97

14. Damasio A (2003) Feelings of emotion and the self. Ann N Y Acad Sci 1001:253-261

15. Duke B, Harper GV, Johnston MK (eds) (2013) Connectivism as a digital age learning theory. Int High Educ Teach Learn Rev, New York

16. Bell F (2011) Connectivism: its place in theory-informed research and innovation in technology-enabled learning. Int Rev Res Open Distance Learn 12(3):98-118

17. Aliakbari F, Parvin N, Heidari M, Haghani F (2015) Learning theories application in nursing education. J Educ Health Promot $4: 2$

18. Driscoll MP (2000) Psychology of learning for instruction, 2nd edn. Allyn \& Bacon, Boston

19. Steffens K (2015) Competences, learning theories and MOOCs: recent developments in lifelong learning. Eur J Educ 50(1):41-59

20. Corsonello A, Roller-Wirnsberger R, Di Rosa M, Fabbietti P, Wirnsberger G, Kostka T et al (2018) Estimated glomerular filtration rate and functional status among older people: a systematic review. Eur J Intern Med 56:39-48

21. Corsonello A, Tap L, Roller-Wirnsberger R, Wirnsberger G, Zoccali C, Kostka T et al (2018) Design and methodology of the screening for CKD among older patients across Europe (SCOPE) study: a multicenter cohort observational study. BMC Nephrol 19(1):260

22. Moodle Pty Ltd (1999) Moodle. https://moodle.org/. Accessed 21 Mar 2019

23. Ebner M, Kopp M (2015) iMooX-Publikationen rund um das Pionierprojekt. Druckerei \& Verlag Mayer GmbH \& CO KG, Weinitzen

24. Maxon Computer GmbH (2019) Maxon. https://www.maxon.net/ de/. Accessed 9 Sept 2019

25. Mehmet K, Hakan A (2015) A theoretical analysis of Moocs types from a perspective of learning theories. Proc Soc Behav Sci 186:15-19

26. Spyropoulou N, Pierrakeas C, Kameas A (2014) Creating MOOC guidelines based on best practices. In: 6th international conference on education and new learning technologies

27. Ruiz JG, Mintzer MJ, Leipzig RM (2006) The impact of E-learning in medical education. Acad Med 81(3):207-212

28. Ramnanan CJ, Pound LD (2017) Advances in medical education and practice: student perceptions of the flipped classroom. Adv Med Educ Pract 8:63-73

29. Goldberg LR, Bell E, King C, O'Mara C, McInerney F, Robinson A et al (2015) Relationship between participants' level of education and engagement in their completion of the understanding dementia massive open online course. BMC Med Educ 15:60

30. Alonso Galban P, Vialart Vidal N (2019) Digital literacy program for the use of social media, aimed at health professionals. Stud Health Technol Inform 264:1895-1896

Publisher's Note Springer Nature remains neutral with regard to jurisdictional claims in published maps and institutional affiliations. 